\title{
Soyasaponin I, III, and Soyasapogenol B Inhibit Proliferation and Modulate PKC Expression in Caco-2 Human Colon Cancer Cells
}

\author{
Joseph Salyer $^{1}$, Satchithanandam Eswaranandam ${ }^{1} \&$ Sun-Ok Lee ${ }^{1}$ \\ ${ }^{1}$ Department of Food Science, University of Arkansas, Fayetteville, AR, United States \\ Correspondence: Sun-Ok Lee, Department of Food Science, University of Arkansas, 2650 N Young Avenue, \\ Fayetteville, AR 72704, United States. Fax: 1-479-575-6936; Tel: 1-479-575-6921. E-mail: sunok@uark.edu
}

Received: March 29, 2013 Accepted: July 1, 2013 Online Published: July 10, 2013

doi:10.5539/jfr.v2n4p81 URL: http://dx.doi.org/10.5539/jfr.v2n4p81

\begin{abstract}
Group B saponins, the predominant form of saponins in heat-treated soy products, have been shown to possess hypocholesterolemic, antimutagenic, and anticarcinogenic properties. Previous studies have evaluated crude mixtures of soyasaponins, but studies evaluating a single purified soyasaponin as an anticarcinogenic agent are limited. The goal of this study is to examine the effects of purified soyasaponins I and III as well as their aglycone form, soyasapogenol B, as anticarcinogenic agents on the human colon adenocarcinoma cell line (Caco-2). Experiments were conducted to examine the effects of purified soyasaponins on cell proliferation, Protein Kinase C (PKC) activity, and cell morphology in Caco-2 cell cultures. Treatment of cells with soyasaponins I and III at concentrations of $0.3-0.9 \mathrm{mg} / \mathrm{ml}$ significantly reduced viable cell numbers after 48 and 72 hours of exposure by 8.6-65.3\% $(\mathrm{p}<0.05)$. Soyasapogenol B at a concentration of $0.15 \mathrm{mg} / \mathrm{ml}$ significantly reduced viable cell numbers after 24 hours by $62.4 \%(\mathrm{p}<0.05)$. Cell morphology changes demonstrated that as concentrations and lipophilicity of soyasaponins increased, cell membranes became rougher and more irregular. Treatment of cells for 72 hours significantly reduced the amount of PKC activity by $9-40 \%(p<0.05)$. Results indicate that purified soyasaponins I, III and soyasapogenol B can suppress Caco-2 colon cancer cell proliferation. These findings suggest that purified group B soyasaponins and their final metabolite soyasapogenol B may be a colon-cancer suppressive component of soy that warrants further examination as a potential nutraceutical or functional food.
\end{abstract}

Keywords: soyasaponins I and III, soyasapogenol B, Caco-2, cell proliferation, Protein Kinase C (PKC) activity

\section{Introduction}

Colorectal cancer is the third most commonly diagnosed cancer and is the second leading cause of mortality in the U.S., causing an estimated 49,920 deaths in 2009 in addition to the 146,970 new cases that were also reported (Jemal et al., 2009). The distribution of certain cancer types and target organs is distributed unequally among different countries, people living in urban/rural areas, their socioeconomic status, ethnicities, race, and sex (Schottenfeld \& Beebe-Dimmer, 2005). Variations in cancer risk and development are inevitably due to genetic variations, environmental factors, and diet. Of these factors, diet seems to have the greatest impact on likelihood of developing colon cancer (Wiseman, 2008). Epidemiologic studies have identified an inverse association between diets rich in plant foods and colon cancer (Greenwald, Clifford, \& Milner, 2001; Fung et al., 2003; Chiu et al., 2003); moreover, diets in which soybeans serve as a source of protein may also reduce cancer risk (Byers et al., 2002).

Soybeans contain a variety of phytochemicals that may contribute to its anticancer effects. These include isoflavones, phytosterols, protease inhibitors, phytic acid, and saponins. Soybean saponins are a group of amphiphilic and structurally complex glycosides that consist of one or more oligosaccharide moieties linked to a triterpenoid aglycone ring structure (sapogenol). The name saponin comes from the Latin word for soap "sapo" because of their surface-active properties, which are a result of their hydrophilic sugars and lipophilic sapogenol (Shi et al., 2004). Soyasaponins vary in the composition of their sapogenol as well as the number, type, and point(s) of attachment of their sugar moieties to the sapogenol.

There have been multiple in vitro studies (Tsai, Chen, Chien, Huang, \& Lin, 2010; Kim, Yu, Kim, Kim, \& Sung, 2004; Oh \& Sung, 2001; Rao \& Sung, 1995; Sung, Kendall, Koo, \& Rao, 1995a and 1995b; Bachran C., Bachran, S., Sutherland, Bachran, D., \& Fuchs, 2008; Berhow, Wagner, Vaughn, \& Plewa 2000; Ellington, 
Berhow, \& Singletary, 2005, 2006; Gurfinkel \& Rao, 2003; Hu, Reddy, Hendrich, \& Murphy, 2004a; Hu, Zheng, Hyde, Hendrich, \& Murphy, 2004b) and one in vivo study (Koratkar \& Rao, 1997) conducted to investigate the anti-mutagenic or anti-carcinogenic properties of soyasaponins. These studies have shown soyasaponins suppress the growth of cancer cells and the effect of soy saponins depend on the type of saponin, dose and cancer cell lines tested. Soyasaponin I had no effect on HT-29 colon cell growth (Sarkar \& Li, 2003, Gurfinkel \& Rao, 2003), but it decreased the migratory ability of B16F10 melanoma cells (Chang, Yu, Lin, Wang, \& Tsai, 2006). Tsai et al. (2010) reported that when WiDr human colon cancer cells treated with $0.15,0.30,0.60 \mathrm{or} 1.2 \mathrm{mg} / \mathrm{ml}$ of crude soy saponin, the number of viable cells decreased in a dose-dependent manner and suppressed 12-Otetradecanol-phorbol-13-acetate-stimulated PKC activity $(\mathrm{P}<0.05)$. Other biological activities such as Hepatoprotective activity on human-liver-derived cell line (HepG2 cells) also greatly differ with the type of saponins. Soyasapogenol B monoglucuronide showed the most potent hepatoprotective activity against tert-butyl hydroperoxide toxicity followed by soyasapogenol B itself. Soyasaponin III was weakly protective, while soyasaponin I increased the toxicity of tert-butyl hydroperoxide (Kinjo et al., 2003). The majority of these studies utilized crude mixtures of all group-A and group-B soyasaponins, DDMP group-B soyasaponins, or non-DDMP group-B soyasaponins. The concentrations used in these studies range from $0.00625-2.4 \mathrm{mg} / \mathrm{ml}$ and yield different degrees and types of cancer cell suppression.

The use of crude extracts makes it difficult to compare the results observed in the cells to a molecular action of a specific soyasaponin. Additionally, it is unlikely that these crude mixtures of soyasaponins would continue to exist in their intact forms long enough in the G.I tract to be bioactive in the large intestine or colon. Metabolism and bioavailability studies in animals (Gestetner, Birk, \& Tencer, 1968; Yoshikoshi et al., 1995) and humans (Hu et al., 2004a) demonstrate that soyasaponins do not exist in their intact form in the G.I. tract, and that they are metabolized by gut microflora into their aglycone soyasapogenol. To better understand this process, $\mathrm{Hu}$ et al. (2004b) conducted a human fecal metabolism study which tracked the metabolism of the primary soyasaponin in heat treated soy foods, soyasaponin I (Murphy, Hu, Barua, \& Hauck, 2008). The results show that soyasaponin I is rapidly metabolized within the first 24 hours by microflora into soyasaponin III. The accumulation of soyasaponin III is only transient though, at the end of 48 hours of incubation, soyasapogenol B was all that remained. These results confirm that group B soyasaponins are metabolized by gut microflora and that soyasaponins are hydrolyzed sequentially to yield smaller and more hydrophobic metabolites.

Results from Hu et al. (2004a and 2004b) and animal metabolism studies (Gestetner et al., 1968; Yoshikoshi et al., 1995) indicates that it may not be practical to test crude mixtures of soyasaponins on human colon cancer cells in vitro, simply because soyasaponins are quickly metabolized by gut microflora and may not be present long enough or in significant quantities to have an effect within the colon. Therefore, it would be more pertinent to test the metabolites of soyasaponins rather than the native soyasaponins themselves. Therefore, the objective of the present study was to evaluate the effects of two primary metabolites, soyasaponin III and more importantly, soyasapogenol B and their native form soyasaponin I on the proliferation, cell morphology, and PKC enzyme activity in the Caco-2 human colon adenocarcinoma cell line.

\section{Materials and Methods}

\subsection{Soyasaponin I, III, and Soyasapogenol B Preparation}

Soyasaponins I and III were isolated from whole soybeans as well as from a mixture of soyasaponins that was generously provided by Organic Technologies (Coshocton, $\mathrm{OH}$ ). Total group B soyasaponins were extracted from whole soybeans using a modified method from Hu, Lee, Hendrich and Murphy (2002). HPLC analysis of the resulting soybean extract showed 10 different soyasaponins, there were no interfering isoflavones present. The soybean extract was used as the starting material for alkaline hydrolysis.

Alkaline hydrolysis was used to convert DDMP-conjugated soyasaponins into non-DDMP soyasaponins, which was necessary for acquiring soyasaponins I and III. A modified method from Zhang, Teng and Popovich (2009) was used for the alkaline hydrolysis. Soyasaponins V, I, II, and III were obtained in this manner via fractionation by Shimadzu semi-prep HPLC system equipped with a pump, detector, manual injector, and workstation (Shimadzu, Columbia, MD) using a reverse phase C-18 column (YMC-Pack ODS-AM S $5 \mu \mathrm{m} 12 \mathrm{~nm}, 250 \mathrm{x}$ $10 \mathrm{~mm}$ i.d., YMC, Clifton, NJ). Soyasapogenol B was produced by acid hydrolysis using group B soyasaponins provided by Organic Technologies (Coshocton, OH) and a modified method from Hu et al. (2004a). The hydrolysis product was purified further via semi-prep HPLC as described earlier.

\subsection{Cell Culture}

Caco-2 human colon cancer cells were purchased from the American Type Culture Collection (ATCC, Rockville, MD) at passage number 18 and cultured in Dulbecco's modified eagle's medium (DMEM) supplemented with 10\% 
fetal bovine serum (FBS), $1 \%$ Non-essential amino acids, $2 \%$ antibiotic-antimicotic, and incubated at $37^{\circ} \mathrm{C}$ in a humidified 5\% $\mathrm{CO}_{2}$ atmosphere. All media components and reagents were obtained from Gibco ${ }^{\circledR}$ through Life Technologies (Carlsbad, CA).

\subsection{Cell Proliferation}

Cells at passage numbers 30-31 were used for proliferation assays. Cellular proliferation and viability were measured using the CellTiter $96^{\circledR}$ AQueousOne Solution Cell Proliferation Assay (Promega Corp. Madison, WI). Caco-2 cells $\left(2 \times 10^{3}\right)$ in $100 \mu$ l of DMEM media containing $10 \%$ fetal bovine serum were seeded in the wells of a 96 well plate and incubated at $37{ }^{\circ} \mathrm{C}$ and $5 \% \mathrm{CO}_{2}$. After stable attachment ( $\left.48 \mathrm{hrs}\right)$, media was removed and replaced with test media containing soyasaponins I and III at concentrations of $0,0.3,0.6$, and $0.9 \mathrm{mg} / \mathrm{ml}$, and soyasapogenol B at concentrations of $0,0.05,0.10$, and $0.15 \mathrm{mg} / \mathrm{ml}$.

Proliferation measurements were made at $0,24,48$, and $72 \mathrm{hrs}$. Cell Titer reagent $(20 \mu \mathrm{l})$ was added directly to the wells containing cells as well as those wells containing only the test media (to be used as a sample control) and incubating for 4 hours before measuring the absorbance at $490 \mathrm{~nm}$. After all absorbance readings had been made, corrections were made for the background absorbance of the control media as well as the sample control media, which contained soyasaponins. Absorbance was converted into cell numbers using an equation from the Caco-2 cell standard curve Figure 1.

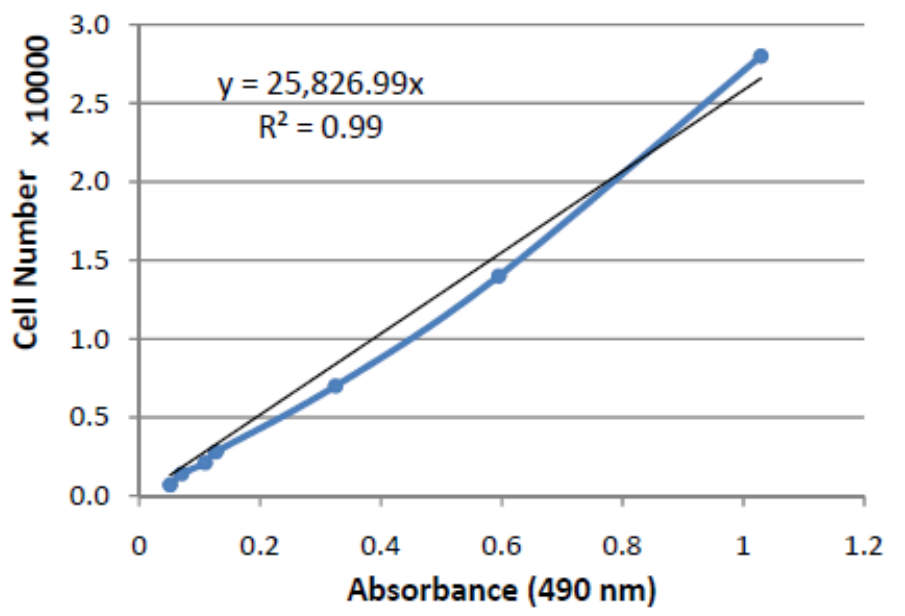

Figure 1. Serial dilution of cells was prepared in triplicate ranging from 350-28,000 cells per ml. Absorption of formazan by-product at $490 \mathrm{~nm}$ is directly proportional to cell number

\subsection{PKC Assay}

Cells at passage numbers 35-40 were used for PKC enzyme activity assays. PKC activity was determined with the PepTag ${ }^{\circledR}$ Non-Radioactive PKC assay kit (Promega Corp. Madison, WI). The PepTag ${ }^{\circledR}$ Assay utilizes a brightly colored fluorescent peptide that it highly specific for PKC, which phosphorylates the PKC peptide, thus changing its net charge from +1 to -1 . The change in net charge of the substrate allows the phosphorylated and non-phosphorylated versions of the substrate to be rapidly separated on an agarose gel. After electrophoresis, the bands can be excised, re-solubilized, and quantified by reading their absorption on a plate reader at $570 \mathrm{~nm}$.

Caco- 2 cells $\left(5 \times 10^{6}\right)$ were seeded in a $75 \mathrm{~cm}^{2}$ flask. After stable attachment, media was removed and replaced with test media containing $0.3,0.6$, and $0.9 \mathrm{mg} / \mathrm{ml}$ of soyasaponins I and III and $0.05,0.10$, and $0.15 \mathrm{mg} / \mathrm{ml} \mathrm{of}$ soyasapogenol B, as well as media containing no soyasaponins or soyasapogenol B. All media except that of the negative control contained 12-O-tetradecanoyl phorbol 13 acetate (TPA) (100 ng/ml), a known PKC stimulator. The cells were then incubated for $72 \mathrm{hrs}$ at $37{ }^{\circ} \mathrm{C}$ and $5 \% \mathrm{CO}_{2}$. Cells were harvested and homogenized. The cell lysate was centrifuged for 5 minutes at $4{ }^{\circ} \mathrm{C}, 14,000 \mathrm{x}$ g and the supernatant was used according to the directions provided by the manufacturer for determining PKC activity of the sample.

Once electrophoresis of the PKC samples was complete, the gel was removed from the chamber and photographed under UV light to provide for greater sensitivity. Using a scalpel, the negatively charged bands were quickly excised to avoid diffusion. The excised bands were re-solubilized and transferred to a well in a 
96-well plate and absorbance was read at $570 \mathrm{~nm}$. The plate reader was blanked by using liquefied agarose without PapTag ${ }^{\circledR}$ Peptide. The activity of PKC in the samples was then calculated using the absorbance seen in the PKC positive control.

\subsection{Light Microscopic Observation of Cells}

Cell morphology was observed using a Nikon Eclipse E400 light microscope with Nikon Camera Head DS-Fi1. Cells from passage number 41 were used to visualize morphology changes.

After 72 hours of treatment with soyasaponin I, III, or soyasapogenol B, cells were harvested and an aliquot was taken from the cell suspension. A portion of the aliquot was then stained with trypan blue dye to determine viable from non-viable cells and also to provide contrast. The prepared slides were viewed under low power magnification until an acceptable cell was identified. The cell of interest was then viewed under higher power $(400 \mathrm{x})$. Using the Nikon camera software, contrast and color was adjusted to provide the best possible image, after which, a still shot was taken and saved for later viewing.

\subsection{Statistical Analysis}

Data was analyzed using Statistical Analysis System (Version 9.2; SAS Institute Inc., Cary, NC). Results were analyzed using one-way analysis of variance using an alpha level of 0.05 followed by Fisher's least significant difference (LSD) test. Data are presented as means \pm standard deviation (SD).

\section{Results}

\subsection{Soyasaponins I, III, and Soyasapogenol B Inhibit Proliferation of Caco-2 Cells}

Treatment of cultures of Caco-2 cells with soyasaponins I, III and soyasapogenol B decreased cell proliferation in a time and concentration-dependent manner (Figures 2-4). As early as $24 \mathrm{~h}$ after initiation of soyasapogenol B treatment, viable cell numbers were significantly reduced by $62.4 \%$ (Figure 2 Cell numbers from 44,653 to 16,802), compared with the control, at concentrations of $0.150 \mathrm{mg} / \mathrm{ml}(\mathrm{p}<0.05)$. After 48 hours soyasapogenol $\mathrm{B}$ treatment reduced viable cell numbers significantly even at $0.05 \mathrm{mg} / \mathrm{ml}$ concentration (66.8-93.8\%). After $48 \mathrm{~h}$ of treatment, Soyasaponins I and III at all concentrations reduced viable cell numbers by 8.6-26.7 and 13.7-35.1\%, respectively ( $\mathrm{p}<0.05$ Figures 3 and 4$)$. Similarly, after $72 \mathrm{~h}$ of treatment by soyasaponins I, III, viable cell numbers were significantly reduced by $46.2-60.1$ and $48.4-65.3 \%$, respectively, compared with the control $(\mathrm{p}<0.05)$.

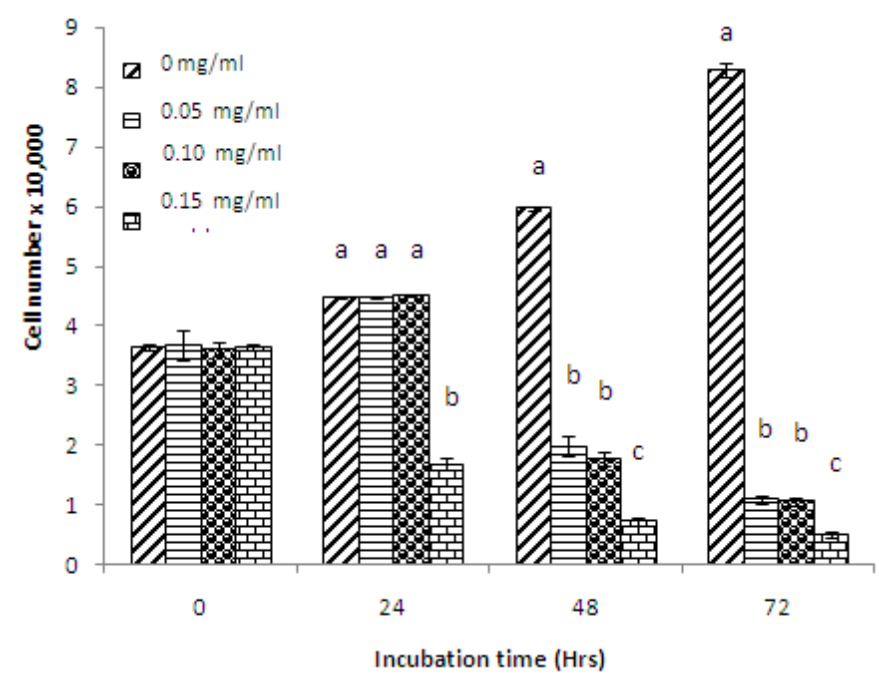

Figure 2. Effect of soyasapogenol B on the survival of Caco-2 cells incubated at $37{ }^{\circ} \mathrm{C}$ and $5 \% \mathrm{CO}_{2}$. Values are means of triplicate analysis. Error bars represents standard deviation. Bars marked with different letters at the same incubation time are significantly different $(p<0.05)$ 


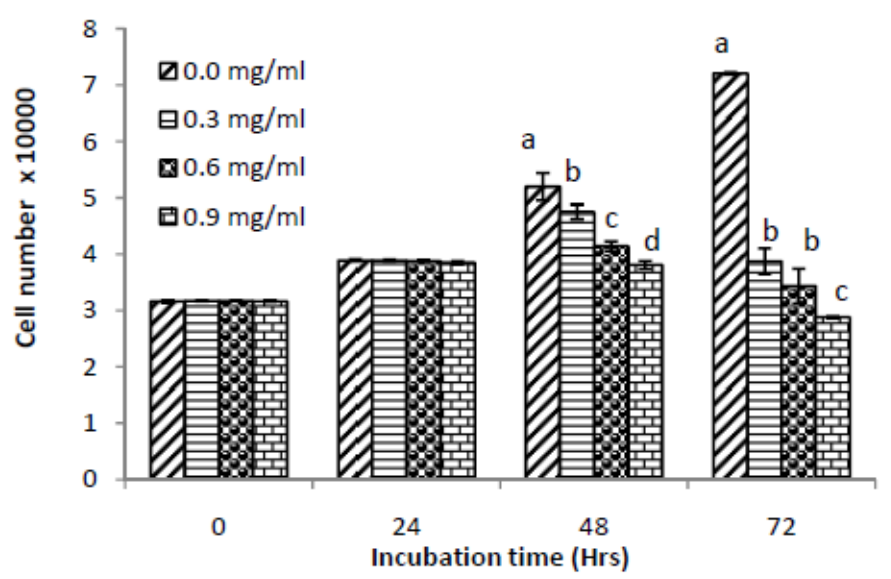

Figure 3. Effect of soyasaponin I on the survival of Caco-2 cells incubated at $37{ }^{\circ} \mathrm{C}$ and $5 \% \mathrm{CO}_{2}$. Values are means of triplicate analysis. Error bars represents standard deviation. Bars marked with different letters at the same incubation time are significantly different $(p<0.05)$

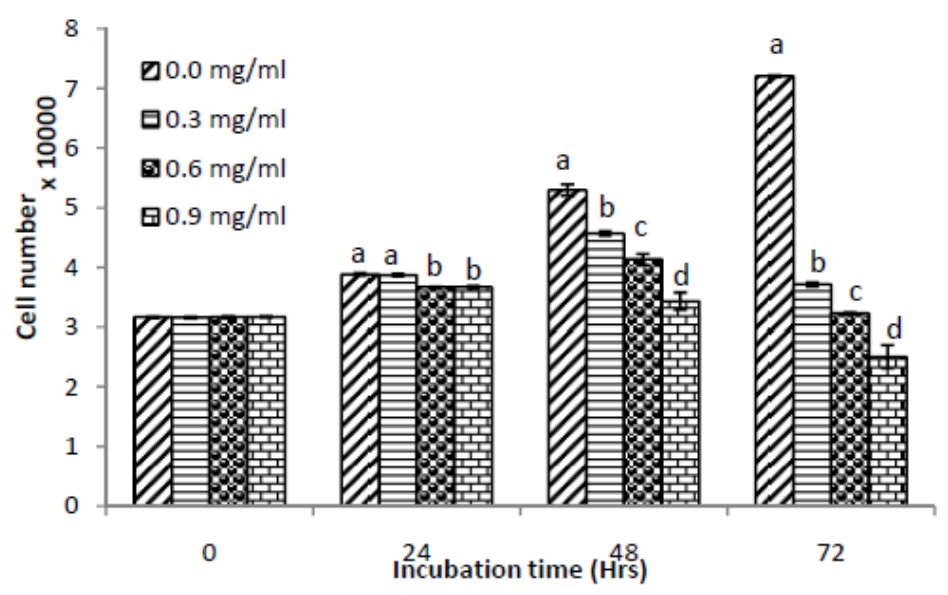

Figure 4. Effect of soyasaponin III on the survival of Caco-2 cells incubated at $37{ }^{\circ} \mathrm{C}$ and $5 \% \mathrm{CO}_{2}$. Values are means of triplicate analysis. Error bars represents standard deviation. Bars marked with different letters at the same incubation time are significantly different $(p<0.05)$

\subsection{PKC Assay}

Expression of the proliferation enzyme PKC was decreased in cells treated with soyasaponins I, III (Figure 5), and soyasapogenol B. Soyasaponin I reduced PKC expression in a dose-dependent manner, ranging from 9.0-27.3\% reduction in PKC activity compared to the control $(\mathrm{p}<0.05)$. Soyasaponin III also reduced PKC activity in a dose-dependent manner. Reductions of $18.2-40.0 \%$ were seen in the soyasaponin III group ( $p<$ 0.05). The soyasapogenol B group showed reductions in PKC ranging between 56.4-70.9\%. The 0.10 and 0.15 $\mathrm{mg} / \mathrm{ml}$ groups showed significantly greater reductions than the $0.05 \mathrm{mg} / \mathrm{ml}$ group $(\mathrm{p}<0.05)$, but $0.15 \mathrm{mg} / \mathrm{ml}$ was not significantly greater than the $0.10 \mathrm{mg} / \mathrm{ml}$ group. 


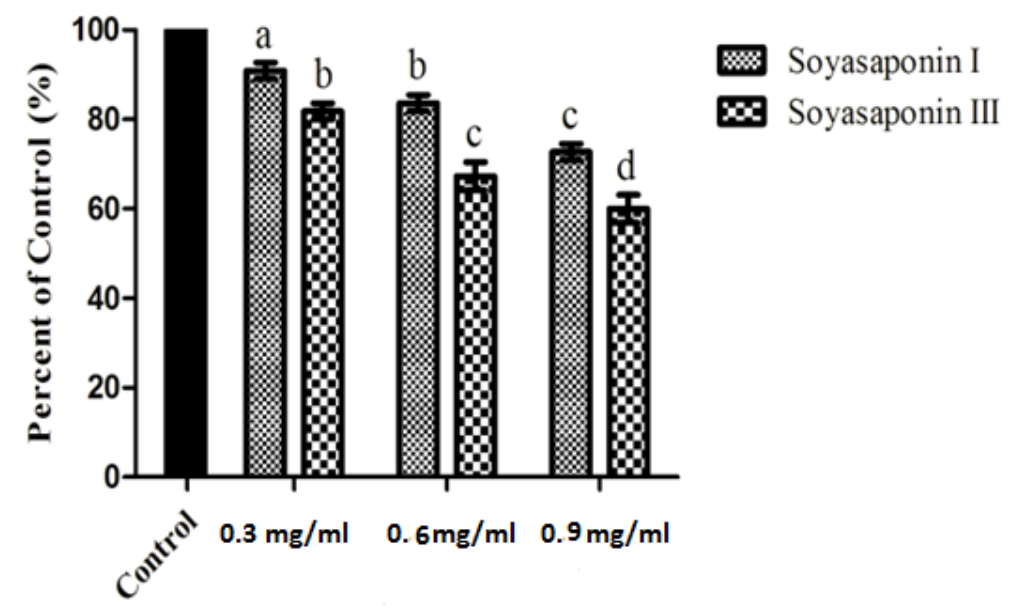

\section{Concentration}

Figure 5. Effect of soyasaponin I and soyasaponin III on PKC expression in Caco-2 cells. Values are means of triplicate analysis. Error bars represents standard deviation. Bars without common lettering are significantly different $(p<0.05)$

\subsection{Light Microscopy}

Figure 6 shows the light microscope observations of Caco-2 cells treated with $0,0.3,0.6$, and $0.9 \mathrm{mg} / \mathrm{ml}$ of soyasaponins I and III (b-g) as well as $0.05,0.10$, and $0.15 \mathrm{mg} / \mathrm{ml}$ of soyasapogenol B (h-j). When the dose of soyasaponins increased, the surface of Caco-2 cells became rougher, and the cell shape changed from round to irregular. As the dose of soyasaponin I and III reached $0.9 \mathrm{mg} / \mathrm{ml}$, breaks were seen on the surface of Caco-2 cells. At the highest concentrations of soyasapogenol B, complete deformation of Caco-2 cells was observed (Figure $6(\mathrm{j})$ ).

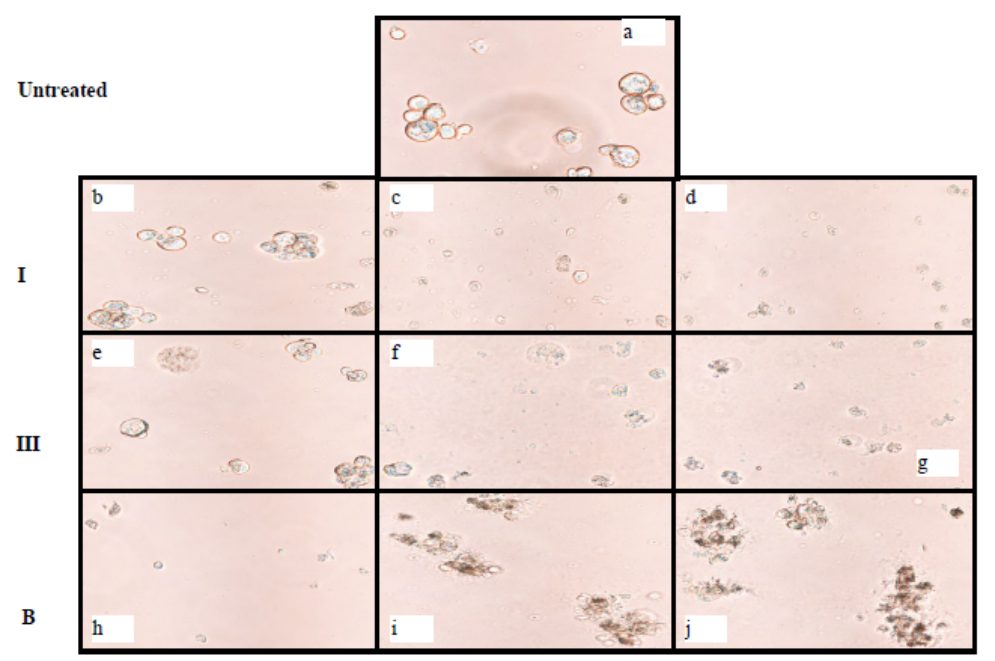

Figure 6. Light microscopic image of a single Caco-2 cell (x400). (a) Untreated; soyasaponin I treated at (b) 0.3 $\mathrm{mg} / \mathrm{ml}$, (c) $0.6 \mathrm{mg} / \mathrm{ml}$, (d) $0.9 \mathrm{mg} / \mathrm{ml}$; soyasaponin III treated at (e) $0.3 \mathrm{mg} / \mathrm{ml}$, (f) $0.6 \mathrm{mg} / \mathrm{ml}$, (g) $0.9 \mathrm{mg} / \mathrm{ml}$; soyasapogenol B treated at (h) $0.05 \mathrm{mg} / \mathrm{ml}$, (i) $0.10 \mathrm{mg} / \mathrm{ml}$, (j) $0.15 \mathrm{mg} / \mathrm{ml}$

\section{Discussion}

In the present study, the effects of the predominant soyasaponin in heat treated soy products (soyasaponin I) as well as its two primary metabolites (soyasaponin III and soyasapogenol B) effectively inhibited the growth rate and survival of Caco-2 human colon cancer cells, altered cell morphology, and inhibited TPA-stimulated PKC activity in a dose-dependent manner. 
Soyasaponins I, III and soyasapogenol B decreased cell proliferation in human colon cancer cells in a time and concentration-dependent manner (Figures 2-4). Previous studies (Bachran et al., 2008; Berhow et al., 2000; Ellington et al., 2005, 2006; Koratkar \& Rao, 1997) utilizing different cell lines (HT-29 and HCT-15), different soyasaponin mixtures, and concentrations, demonstrated less cell growth inhibition than the current study. When reaching the 48 and 72 hour time points in the previously listed studies, cell growth curves of soyasaponin mixtures were still progressing steadily upwards, but in the present study, cells growth plateaus after 24 hours or begin to die off after 48 hours eventually returning to near 0 hour cell numbers after 72 hours. Growth of Soyasapogenol B treated cells shows a different trend because of its increased bioactivity. Cells treated with soyasapogenol B at 0.05 and $0.10 \mathrm{mg} / \mathrm{ml}$ begin to proliferate up to 24 hours, but after which, cell proliferation stops and cell viability drops off dramatically leading up to the 48 and 72 hour time points (Figure 2).

PKC is one of the markers for cell proliferation and its activity increases as the cells undergo the proliferation process. As shown in this study, the addition of soyasaponins I, III, and soyasapogenol B to the cell culture media effectively reduced the expression of PKC in colon cancer cells. Previous research (Kim et al., 2004; Oh \& Sung, 2001; Rao \& Sung, 1995) has shown similar results when using crude mixtures of group B soyasaponins and HT-29 colon cancer cells.

In the current study, there was a dose-dependent effect seen in the soyasaponin I group. For the $0.3,0.6$, and 0.9 $\mathrm{mg} / \mathrm{ml}$ groups, PKC activity was reduced by $9.1,16.4$, and $27.3 \%$ respectively (Figure 5). Soyasaponin III followed a similar pattern with reductions of: $18.2,32.7$, and $40.0 \%$. Depending on the soyasaponin, the percent reductions in PKC activity of this study are close to those of the previously mentioned studies (Tsai et al., 2010; Kim et al., 2004; Oh \& Sung, 2001) which used soyasaponin mixtures. Soyasaponin I reduction was less than the reported values in these studies when used at the same concentrations, but soyasaponin III had a greater reduction at the $0.6 \mathrm{mg} / \mathrm{ml}$ concentration compared to mixtures of soyasaponins at that same concentration.

Initially, it appeared that the soyasapogenol B group had reduced the PKC activity of the cells by 56.4, 65.5 , and $70.9 \%$. However, because of its increased bioactivity, after 72 hours cell viability was extremely low, therefore, the measured reduction in PKC activity may not have been due to reduced expression of the protein by the cells, but rather because the cells were no longer alive to produce the protein.

A previous report has indicated that soyasaponins possess surface-active properties (Sung et al., 1995a). Transmission electron microscopy imaging indicates that soyasaponins induced the formation of vacuoles and deformations in plasma and nuclear membranes of cells (Ellington et al., 2006). Previous studies have suggested that the disruption caused by soyasaponins somewhat modulates the translocation of PKC from the cytosol to the cell membrane (Oh \& Sung 2001; Rao \& Sung, 1995), thus reducing its expression. As mentioned earlier, soyasaponin-cell membrane interactions appear to be the key mechanism by which soyasaponins elicit their effects.

It became evident that when treated with increasing concentrations of soyasaponins and soyasapogenol B, cell membranes became more rough and irregular. At the highest concentrations of soyasaponin and soyasapogenol B, complete deformation of Caco-2 cells was observed (Figure 6). Similar results were seen by Tsai et al. (2010). Changes in cell morphology are suggestive that soyasaponins may be binding to or inserting into the cell membrane. This is particularly relevant because the membranes of some cancer cells contain more cholesterol than normal cell membranes. Because of this, it is also likely that soyasaponins bind more to cancer cells than normal epithelial cells, and thus in the intestine, soyasaponins can bind to the mucosal cell membrane, change its physiology, and as a result reduce cancerous cell growth.

Proliferation and viability data, PKC expression, and microscopy results from this study all indicate that the bioactivity of soyasaponins and soyasapogenol $\mathrm{B}$ are directly related to their molecular structure and more importantly their lipophilicity. The differences in bioactivity are likely due to the fact that with increases in lipophilicity, there is more soyasaponin/ soyasapogenol B interaction with the phospholipids and cholesterol of cancer cell membranes.

\section{Conclusions}

In summary, cell proliferation and PKC activity were reduced in a dose-dependent manner when treated with the predominant soyasaponin in heat treated soy products, soyasaponin I and its two metabolites. Data from proliferation and PKC assays as well as morphological analysis indicates that the suppression of cell growth and disruption of cell membrane integrity is intensified with increases in lipophilicity of the soyasaponins and soyasapogenol B, meaning that soyasapogenol B is greater than soyasaponin III which is greater than soyasaponin I. The results of this study indicate that the predominant soyasaponin in heat treated soy products and its two metabolites, at physiologically relevant doses, can suppress colon cancer growth. These findings 
suggest that purified soyasaponins and soyasapogenol B may be a colon cancer suppressive component of soy which warrants further examination as a potential nutraceutical or functional food.

\section{Acknowledgements}

This work was supported by the National Science Foundation-EPSCoR (Center for Plant-Powered Production) at the University of Arkansas.

\section{References}

Bachran, C., Bachran, S., Sutherland, M., Bachran, D., \& Fuchs, H. (2008). Saponins in Tumor Therapy. Mini Rev. Med. Chem., 8(6), 575-584. http://dx.doi.org/10.2174/138955708784534445

Berhow, M. A., Wagner, E. D., Vaughn, S. F., \& Plewa, M. J. (2000). Characterization and antimutagenic activity of soybean saponins. Mutat. Res., 448(1), 11-22. http://dx.doi.org/10.1016/S0027-5107(99)00225-0

Byers, T., Nestle, M., McTiernan, A., Doyle, C., Currie-Williams, A., Gansler, T., \& Thun, M. (2002). American Cancer Society 2001 Nutrition and Physical Activity Guidelines and Advisory Committee. American Cancer Society guidelines on nutrition and physical activity for cancer prevention: reducing the risk of cancer with healthy food choices and physical activity. CA Cancer J. Clin., 52, 92-119. http://dx.doi.org/10.3322/canjclin.52.2.92

Chang, W. W., Yu, C. Y., Lin, T. W., Wang, P. H., \& Tsai, Y. C. (2006). Soyasaponin I decreases the expression of alpha2,3-linked sialic acid on the cell surface and suppresses the metastatic potential of B16F10 melanoma cells. BiochemBiophys Res Commun, 341, 614-9. http://dx.doi.org/10.1016/j.bbrc.2005.12.216

Chiu, B., Ji, B., Dai, Q., Gridley, G., Mclaughlin, J. K., Gao, Y., Fraumeni, J. F., \& Chow, W. (2003). Dietary factors and risk of colon cancer in Shanghai, China. Cancer Epidemiol. Biomarkers Prev., 12, 201-208.

Ellington, A. A., Berhow, M., \& Singletary, K. W. (2005). Induction of macroautophagy in human colon cancer cells by soybean B-group triterpenoid saponins. Carcinogenesis, 26(1), 159. http://dx.doi.org/10.1093/carcin/bgh297

Ellington, A. A., Berhow, M. A., \& Singletary, K. W. (2006). Inhibition of Akt signaling and enhanced ERK1/2 activity are involved in induction of macroautophagy by triterpenoid B-group soyasaponins in colon cancer cells. Carcinogenesis, 27(2), 298. http://dx.doi.org/10.1093/carcin/bgi214

Fung, T., Hu, F. B., Fuchs, C., Giovannucci, E., Hunter, D. J., Stampfer, M. J., ... Willet, W. C. (2003). Major dietary patterns and the risk of colorectal cancer in women. Arch. Intern. Med., 163, 309-314. http://dx.doi.org/10.1001/archinte.163.3.309

Gestetner, B., Birk, Y., \& Tencer, Y. (1968). Soybean saponins.Fate of ingested soybean saponins and the physiological aspect of their hemolytic activity. J. Agric. Food Chem., 16(6), 1031-1035. http://dx.doi.org/10.1021/jf60160a025

Greenwald, P., Clifford, C. K., \& Milner, J. A. (2001). Diet and cancer prevention. Eur. J. Cancer, 37, 948-965. http://dx.doi.org/10.1016/S0959-8049(01)00070-3

Gurfinkel, D. M., \& Rao, A. V. (2003). Soyasaponins: the relationship between chemical structure and colon anticarcinogenic activity. Nutr. Cancer, 47(1), 24-33. http://dx.doi.org/10.1207/s15327914nc4701_3

Hu, J., Lee, S. O., Hendrich, S., \& Murphy, P. A. (2002). Quantification of the group B soyasaponins by high-performance liquid chromatography. J. Agric. Food Chem., 50(9), 2587-2594. http://dx.doi.org/10.1021/jf0114740

Hu, J., Reddy, M. B., Hendrich, S., \& Murphy, P. A. (2004a). Soyasaponin I and Sapongenol B Have Limited Absorption by Caco-2 Intestinal Cells and Limited Bioavailability in Women. J. Nutr, 134(8), 1867-1873.

Hu, J., Zheng, Y. L., Hyde, W., Hendrich, S., \& Murphy, P. A. (2004b). Human fecal metabolism of soyasaponin I. J. Agric. Food Chem., 52(9), 2689-2696. http://dx.doi.org/10.1021/jf035290s

Jemal, A., Siegel, R., Ward, E., Hao, Y., Xu, J., \& Thun, M. J. (2009). Cancer statistics. CA: a cancer journal for clinicians, 59(4), 225. http://dx.doi.org/10.3322/caac.20006

Kim, H. Y., Yu, R., Kim, J. S., Kim, Y. K., \& Sung, M. K. (2004). Antiproliferative crude soy saponin extract modulates the expression of I [kappa] B [alpha], protein kinase $\mathrm{C}$, and cyclooxygenase-2 in human colon cancer cells. Cancer Lett., 210(1), 1-6. http://dx.doi.org/10.1016/j.canlet.2004.01.009

Kinjo, J., Hirakawa, T., Tsuchihashi, R., Nagao, T, Okawa, M., Nohara, T., \& Okabe, H. (2003). Hepatoprotective constituents in plants.14. Effects of soyasapogenol B, sophoradiol, and their glucuronides 
on the cytotoxicity of tert-butyl hydroperoxide to HepG2 cells. Biol Pharm Bull., 26(9), 1357-60. http://dx.doi.org/10.1248/bpb.26.1357

Koratkar, R., \& Rao, A. V. (1997). Effect of soya bean saponins on azoxymethane-induced preneoplastic lesions in the colon of mice. Nutr. Cancer, 27(2), 206-209. http://dx.doi.org/10.1080/01635589709514526

Murphy, P. A., Hu, J., Barua, K., \& Hauck, C. C. (2008). Group B Saponins in Soy Products in the US Department of Agriculture Iowa State University Isoflavone Database and Their Comparison with Isoflavone Contents. J. Agric. Food Chem., 56(18), 8534-8540. http://dx.doi.org/10.1021/jf800491p

Oh, Y. J., \& Sung, M. K. (2001). Soybean saponins inhibit cell proliferation by suppressing PKC activation and induce differentiation of HT-29 human colon adenocarcinoma cells. Nutri. Cancer, 39(1), 132-138. http://dx.doi.org/10.1207/S15327914nc391_18

Rao, A. V., \& Sung, M. K. (1995). Saponins as anticarcinogens. J. Nutr, 125(3 Suppl), 717S.

Sarkar, F. H., \& Li, Y., (2003). Soy isoflavones and cancer prevention. Cancer Invest, 21, 744-57. http://dx.doi.org/10.1081/CNV-120023773

Schottenfeld, D., \& Beebe-Dimmer, J. (2005). Advances In Cancer Epidemiology: Understanding Causal Mechanisms and the Evidence for Implementing Interventions. Annu. Rev. Public Health, 26(1), 37-60. http://dx.doi.org/10.1146/annurev.publhealth.26.021304.144402

Shi, J., Arunasalam, K., Yeung, D., Kakuda, Y., Mittal, G., \& Jiang, Y. (2004). Saponins from edible legumes: Chemistry, processing, and health benefits. J. Med. Food, 7(1), 67-78. http://dx.doi.org/10.1089/109662004322984734

Sung, M. K., Kendall, C. W., Koo, M. M., \& Rao, A. V. (1995a). Effect of soybean saponins and gypsophilla saponin on growth and viability of colon carcinoma cells in culture. Nutri. Cancer, 23(3), 259-270. http://dx.doi.org/10.1080/01635589509514380

Sung, M. K., Kendall, C. W. C., \& Rao, A. V. (1995b). Effect of soybean saponins and gypsophila saponin on morphology of colon carcinoma cells in culture. Food Chem. Toxicol., 33(5), 357-366. http://dx.doi.org/10.1016/0278-6915(95)00007-O

Tsai, C. Y., Chen, Y. H., Chien, Y. W., Huang, W. H., \& Lin, S. H. (2010). Effect of soy saponin on the growth of human colon cancer cells. World Journal of Gastroenterology: WJG., 16(27), 3371-3376. http://dx.doi.org/10.3748\%2Fwjg.v16.i27.3371

Wiseman, M. (2008). The second World Cancer Research Fund/ American Institute for Cancer Research expert report. Food, nutrition, physical activity, and the prevention of cancer: a global perspective. Proc. Nutr. Soc. 67(3), 253-256. http://dx.doi.org/10.1017/S002966510800712X

Wu, X., \& Kang, J. (2011). Phytochemicals in soy and their health effects, phytochemicals - Bioactivities and Impact on Health, Prof. IrajRasooli (Ed.), Available from http://www.intechopen.com/books/phytochemicals-bioactivities-and-impact-on-health/phytochemicals-in-s oyand-their-health-effects

Yoshikoshi, M., Kahara, T., Yoshiki, Y., Furukawa, Y., Okubo, K., Amarowicz, R., \& Ito, M. (1995). Metabolism and nonabsorption of soybean hypocotyl saponins in the rat model. Acta Alimentaria, 24(4), 355-364.

Zhang, W. Teng, S. P., \& Popovich, D. G. (2009). Generation of Group B Soyasaponins I and III by Hydrolysis. J. Agric. Food Chem., 57, 3620-3625. http://dx.doi.org/10.1021/jf803663j

\section{Copyrights}

Copyright for this article is retained by the author(s), with first publication rights granted to the journal.

This is an open-access article distributed under the terms and conditions of the Creative Commons Attribution license (http://creativecommons.org/licenses/by/3.0/). 